\title{
Analysis of sensorless control of brushless DC motor using unknown input observer with different gains
}

\author{
Mitesh B. Astik, ${ }^{*}$ Praghnesh Bhatt, ${ }^{* *}$ Bhavesh R. Bhalja ${ }^{* * *}$
}

\begin{abstract}
A sensorless control scheme based on an unknown input observer is presented in this paper in which back EMF of the Brushless DC Motor (BLDC) is continuously estimated from available line voltages and currents. During negative rotation of motor, actual and estimated speed fail to track the reference speed and if the corrective action is not taken by the observer, the motor goes into saturation. To overcome this problem, the speed estimation algorithm has been implemented in this paper to control the dynamic behavior of the motor during negative rotation. The Ackermans method was used to calculate the gains of an unknown input observer which is based on the appropriate choice of the eigenvalues in advance. The criteria to choose eigenvalue is to obtain a balance between faster convergence rate and the least noise level. Simulations have been carried out for different disturbances such as step changes in motor reference speed and load torque. The comparative simulation results clearly depict that the disturbance effects in actual and estimated responses minimizes as observer gain setting increases.
\end{abstract}

K e y w o r d s: back EMF estimation, BLDC motor, observer design, observer gain, sensorless control, speed estimation

\section{Introduction}

The use of Brushless DC Motors is extensively increasing for various applications due to their compact and robust structures. Compared to Permanent Magnet Synchronous Motors; the BLDC motors have higher power/weight and higher torque/current ratio [1]. A BLDC motor requires an inverter and position sensors to perform commutation process as the motor does not have commutator and brushes. However, the position sensors present many disadvantages like increase in machine size, reduction in reliability and higher noise. Thus, many researchers have suggested application of sensorless drive which can regulate speed and position without using shaft-mounted position sensors [2]. Main types of sensorless control methods are the back-EMF measurement, third harmonic sensing of back EMF, back EMF integration, flux linkage estimation, freewheeling diode and estimator-based approach [3-12].

The method for measurement of back EMF requires additional power supply for a comparator to detect freewheeling current [3, 4]. Shen et al [5] proposed a scheme to detect the third harmonic of back EMF. This scheme is only valid for high speed as third harmonics detection is difficult due to constant addition of noise signal at minimum speed range. Additional hardware is required to detect the third harmonic of back EMF at minimum speed. In integration of back EMF method, commutation instants can be detected by comparing the threshold value with the integration of the back-EMF waveforms of the unexcited phase. Due to integration process, this method gives an error at low speeds [6-8]. In the flux linkage estimation method, rotor position can be obtained by estimating the flux. As integration of voltage is done for comparatively large time, this scheme also give estimation error at low speeds $[9,10]$. Ogasawara and Akagi [11] proposed an estimation scheme in which rotor position is estimated by detecting switching status of freewheeling diode. In this scheme, current flow through the freewheeling diodes are used to identify the zero crossing of back EMF. This method requires six comparators and six isolated power sources.

Above mentioned methods are not suitable where the high estimation accuracy of speed and position are required as they cannot provide continuous rotor position estimation. Terzic and Jadric [12] proposed a new scheme for estimation of speed and rotor position of a BLDC motor using Extended Kalman Filter (EKF). Only using stator voltages and currents measurements, EKF can estimate the motor state variables. In this method, filtering of voltage and current signals do not required but this method needs complex computing algorithm and it suffers from the initial-value problem.

In this work, sensorless control of the brushless dc motor has been proposed by designing unknown input observer. The observer design requires the input voltage and current signals of BLDC motor to estimate back EMFs which eliminate the need of rotor speed measurement. The observer should be designed to give the optimal performance over wide speed range and in case of reversal of the motor rotation. Generally, the observer fails when the motor reverses its direction of rotation. The perfect

* Department of Electrical Engineering, A. D. Patel Institute of Technology, New Vallabh Vidyanagar, India, ** Department of Electrical Engineering, C. S. Patel Institute of Technology, CHARUSAT, Changa, India, *** Department of Electrical Engineering, Indian Institute of Technology, Roorkee, India, miteshastik@yahoo.com 


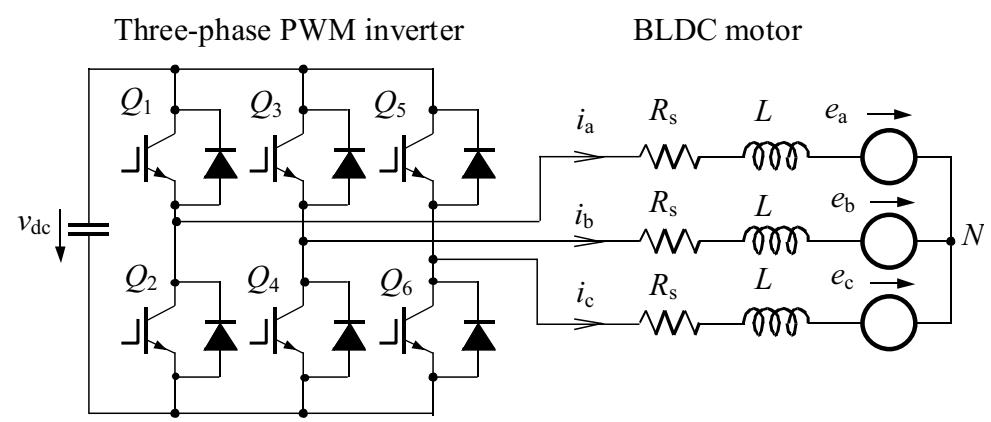

Fig. 1. PWM Inverter connected to BLDC Motor

Table 1. Switching table for IGBTs

\begin{tabular}{lccccccccc}
\hline $\begin{array}{l}\text { Rotor } \\
\text { position } \\
\text { electrical } \\
\text { degree }\end{array}$ & $\begin{array}{c}\text { Reference stator } \\
\text { currents }\end{array}$ & \multicolumn{1}{c}{ IGBT switching sequence } \\
\hline & $i_{a}$ & $i_{b}$ & $i_{c}$ & $Q_{1}$ & $Q_{2}$ & $Q_{3}$ & $Q_{4}$ & $Q_{5}$ & $Q_{6}$ \\
\hline $0-30$ & 0 & -1 & 1 & 0 & 0 & 0 & 1 & 1 & 0 \\
$30-90$ & 1 & -1 & 0 & 1 & 0 & 0 & 1 & 0 & 0 \\
$90-150$ & 1 & 0 & -1 & 1 & 0 & 0 & 0 & 0 & 1 \\
$150-210$ & 0 & 1 & -1 & 0 & 0 & 1 & 0 & 0 & 1 \\
$210-270$ & -1 & 1 & 0 & 0 & 1 & 1 & 0 & 0 & 0 \\
$270-330$ & -1 & 0 & 1 & 0 & 1 & 0 & 0 & 1 & 0 \\
$330-360$ & 0 & -1 & 1 & 0 & 0 & 0 & 1 & 1 & 0 \\
\hline & & & & & & & & &
\end{tabular}
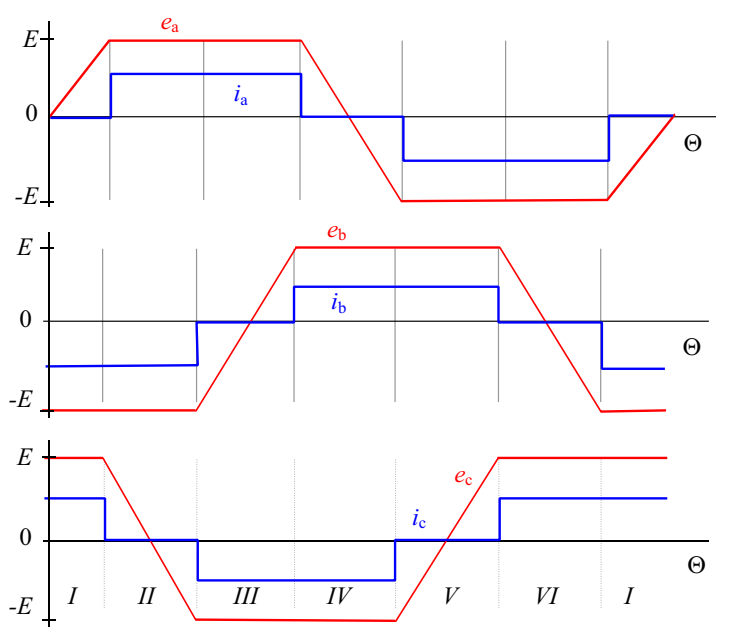

Fig. 2. EMF and phase current waveforms for BLDC motor

tracking of reference speed is required by the actual and estimated speed to avoid the motor to go into saturation especially for negative direction of rotation. Hence, speed estimation algorithm has been implemented to overcome this limitation and different case studies have been presented to validate the proposed approach.

The paper presents modelling of BLDC motor including the observer design for back EMF estimation. The validation of observer design, proposed algorithm and different observer gains, carried out by performing detailed simulations and the results at both transient, and steadystate conditions are provided.

\section{Modelling of BLCD motor}

The brushless dc motor equivalent circuit with threephase PWM inverter is shown in Fig. 1, and the switching sequence of IGBTs is shown in Table 1. Gate signals for IGBTs are generated using commutation signals and comparing the actual and reference current through the hysteresis current controller. The speed and torque can be adjusted by varying the gate pulse of IGBTs.

In case of BLDC motor, the nature of the back EMF is trapezoidal. At any time only two windings are conducting and third winding current is zero [13]. Fig. 2 shows the back-EMFs and phase currents waveform for BLDC motor. To produce constant torque, controlling is required to get quasi square waveform for three-phase stator currents to coordinate with the trapezoidal back EMF [14].

The three-phase voltage equations for the BLDC motor can be written as

$$
\begin{aligned}
& {\left[\begin{array}{c}
V_{a} \\
V_{b} \\
V_{c}
\end{array}\right]=\left[\begin{array}{ccc}
R_{s} & 0 & 0 \\
0 & R_{s} & 0 \\
0 & 0 & R_{s}
\end{array}\right]\left[\begin{array}{c}
i_{a} \\
i_{b} \\
i_{c}
\end{array}\right]+} \\
& +\left[\begin{array}{ccc}
L & 0 & 0 \\
0 & L & 0 \\
0 & 0 & L
\end{array}\right] \frac{\mathrm{d}}{\mathrm{d} t}\left[\begin{array}{c}
i_{a} \\
i_{b} \\
i_{c}
\end{array}\right]+\left[\begin{array}{l}
e_{a} \\
e_{b} \\
e_{c}
\end{array}\right],
\end{aligned}
$$

Where: $V_{a}, V_{b}$ and $V_{c}$ are the per phase stator voltages; $i_{a}, i_{b}$ and $i_{c}$ are per phase stator currents; $R_{s}$ is per phase stator winding resistance; $L=L_{s}-M ; L_{S}$ is 
the per phase stator winding inductance; $M$ is the mutual inductance; $e_{a}, e_{b}$ and $e_{c}$ are the per phase back EMFs.

All stator winding resistances as well as self and mutual inductances are assuming constant [14-15]. Any of the stator phase voltages in (1) can be represented as

$$
v=R i+L \frac{\mathrm{d} i}{\mathrm{~d} t}+e
$$

\section{Observer design for back emf}

In this paper, a sensorless control scheme has been proposed using back EMF estimation. The voltage and current at the stator terminal are measurable quantities, hence they are considered as known state variables. The back EMF of brushless DC motor cannot be measured directly; hence estimation is required with the help of unknown input observer. The time derivative of the stator current with the use of $(2)$ is

$$
\frac{\mathrm{d} i}{\mathrm{~d} t}=-\frac{R}{L} i+\frac{1}{L} v-\frac{1}{L} e,
$$

while the general form of state space representation is

$$
\dot{\mathbf{x}}=\mathrm{Ax}+\mathrm{Bu}, \quad \mathrm{y}=\mathrm{Cx}+\mathrm{Du}
$$

where

$$
\begin{aligned}
& \mathbf{A}=\left[\begin{array}{cc}
a_{11} & a_{12} \\
0 & 0
\end{array}\right], \quad \mathbf{B}=\left[\begin{array}{c}
b_{11} \\
0
\end{array}\right], \quad \mathbf{C}=\left[\begin{array}{ll}
1 & 0
\end{array}\right], \\
& \mathbf{D}=0, \quad \mathbf{x}=\left[\begin{array}{l}
i \\
e
\end{array}\right], \quad \mathbf{y}=\left[\begin{array}{l}
i \\
0
\end{array}\right], \quad \mathbf{u}=\left[\begin{array}{l}
v \\
0
\end{array}\right],
\end{aligned}
$$

and,

$$
a_{11}=-\frac{R}{L}, \quad a_{12}=-\frac{1}{L}, \quad b_{11}=\frac{1}{L} .
$$

Thus, the current and back EMF of the brushless DC motor can be represented in state variable form as

$$
\begin{aligned}
& \frac{d}{d t}\left[\begin{array}{l}
i \\
e
\end{array}\right]=\left[\begin{array}{cc}
a_{11} & a_{12} \\
0 & 0
\end{array}\right]\left[\begin{array}{l}
i \\
e
\end{array}\right]+\left[\begin{array}{c}
b_{11} \\
0
\end{array}\right] v, \\
& \mathbf{y}=\mathbf{C x}=\left[\begin{array}{ll}
1 & 0
\end{array}\right]\left[\begin{array}{l}
i \\
e
\end{array}\right]=i .
\end{aligned}
$$

To design the observer, the back emf is supposed to be a constant disturbance, hence its time derivative $\frac{\mathrm{d} e}{\mathrm{~d} t}=0$. As the system expressed by (5) is totally observable; the state observer can be represented in full-order by

$$
\dot{\hat{\mathbf{x}}}=\mathbf{A} \widehat{\mathbf{x}}+\mathbf{B u}+\mathbf{G}(\mathbf{y}-\widehat{\mathbf{y}}),
$$

where $\mathbf{G}$ is observer gain matrix

$$
\mathbf{G}=\left[\begin{array}{l}
g_{1} \\
g_{2}
\end{array}\right]
$$

From the variations of estimated quantities one finds

$$
\frac{\mathrm{d} \widehat{\mathbf{e}}}{\mathrm{d} t}=g_{2}(\mathbf{i}-\widehat{\mathbf{i}})
$$

Observer error equation, which shows the difference between actual and estimated value, then is

$$
\frac{\mathrm{d}}{\mathrm{d} t}\left[\begin{array}{l}
\xi_{1} \\
\xi_{2}
\end{array}\right]=\left[\begin{array}{cc}
a_{11}-g_{1} & a_{12} \\
-g_{2} & 0
\end{array}\right]\left[\begin{array}{l}
\xi_{1} \\
\xi_{2}
\end{array}\right]
$$

with

$$
\left[\begin{array}{l}
\xi_{1} \\
\xi_{2}
\end{array}\right]=\left[\begin{array}{l}
i-\widehat{i} \\
e-\widehat{e}
\end{array}\right]
$$

The objective is to find out the optimal value of the observer gains and so that the observer error can be reduced to approximately zero. The methods for calculating the observer gains are discussed in next section.

\section{Observer gains calculation}

Ackermans method can be used to determine the state variable feedback gain matrix after placing the system poles at the preferred positions. The desired eigenvalues of the observer are set as $\lambda_{1}$ and $\lambda_{2}$. This will result in following characteristic polynomial.

$$
\begin{gathered}
\alpha(s)=\left(s-\lambda_{1}\right)\left(s-\lambda_{2}\right)= \\
s^{2}-\underbrace{\left(\lambda_{1}+\lambda_{2}\right)}_{-\alpha_{1}} s+\underbrace{\lambda_{1} \lambda_{2}}_{\alpha_{0}} .
\end{gathered}
$$

According to Cayley-Hamilton theorem [11], the characteristic equation can be expressed in terms of matrix $\mathbf{A}$ as

$$
\alpha(\mathbf{A})=\mathbf{A}^{2}+\alpha_{1} \mathbf{A}+\alpha_{0} \mathbf{I},
$$

giving, by the Ackermans formula, the observer gain matrix $\mathbf{G}$, with $\mathbf{Q}$ being the observability matrix for the pair $(\mathbf{A}, \mathbf{C})$

$$
\begin{aligned}
& \mathbf{G}=\left[\begin{array}{l}
g_{1} \\
g_{2}
\end{array}\right]=\alpha(\mathbf{A}) \mathbf{Q}^{-1}\left[\begin{array}{l}
0 \\
1
\end{array}\right]=\left[\begin{array}{c}
a_{11}+\alpha_{1} \\
\alpha_{0} / a_{12}
\end{array}\right] \\
& \mathbf{Q}=\left[\begin{array}{c}
\mathbf{C} \\
\mathbf{C A}
\end{array}\right]=\left[\begin{array}{cc}
1 & 0 \\
a_{11} & a_{12}
\end{array}\right]
\end{aligned}
$$

For stator resistance $R_{s}=0.2 \Omega$ and inductance $L=8.5 \mathrm{mH}, a_{11}=-23.53$ and $a_{12}=-117.65$ are obtained. By choosing eigen values $\lambda_{1,2}=-1000 \pm j 1200$ for the above mentioned motor parameters resulting in $\alpha_{0}=2440000$ and $\alpha_{1}=2000$ the observer gains are $g_{1}=197647$ and $g_{2}=-20740$. In this paper, different eignvalues $i e-1000 \pm j 1200,-2500 \pm j 4000$, and $-1500 \pm j 8000$, were chosen to validate the effect of observer gains on the motor performance.

The selection of the gains and the eigenvalues for the observer design are interrelated. The choice of the eigenvalue is very critical to get the optimal performance. The 


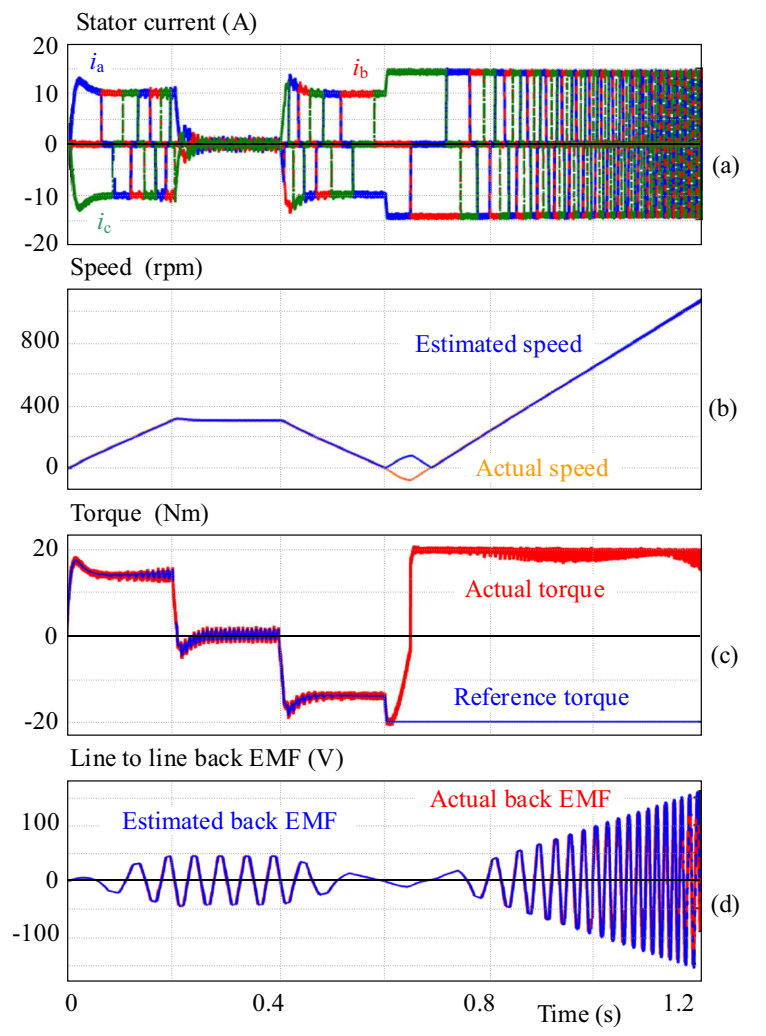

Fig. 3. Dynamic responses of stator currents, speeds, torques and back EMFs of phase-ab for the change in reference speed from 300 rpm to $0 \mathrm{rpm}$ to $300 \mathrm{rpm}$, keeping load torque $\left(T_{L}\right)=0$ without using speed estimation algorithm

smaller value of the eigenvalue makes the response sluggish. Theoretically, the eigenvalues can be moved arbitrarily toward minus infinity, yielding faster convergence rate. However, observer act like a differentiator and it becomes very sensitive to noise and other disturbances for very large eigenvalues [19]. Hence, the eigenvalues are chosen to have a balance between the faster convergence rate and the least sensitivity to noise.

\section{Proposed algorithm and simulation block diagram for BLCD motor}

First the motor speed is estimated with the ratio of estimated back EMF to torque constant [20]. Then proposed speed estimation algorithm is implemented correctly to control the motor speed when reference speed becomes negative. The complete block diagram representation of the proposed sensorless control of brushless dc motor is discussed further.

\subsection{Rotor speed and position estimation}

The estimated speed of the motor is expressed as the ratio of estimated back EMF to torque constant and given by

$$
\widehat{\omega}_{m}=\frac{\widehat{e}}{k_{T}}
$$

where, $k_{T}$ is torque constant [21] given by

$$
k_{T}=\lambda_{p} \frac{P}{2}
$$

where, $P$ - number of poles, $\lambda_{p}$ - flux linkage established by magnets.

Figure 3 shows the dynamic responses of currents, speeds, torques and line to line back EMFs for change in reference speed for every $0.4 \mathrm{~s}$ without the use of speed estimation algorithm. As shown in Fig. 3, the motor works satisfactory for positive rotation $i e$ up to $0.6 \mathrm{~s}$. When the reference speed signal becomes zero, the actual speed becomes negative as undershoot occurs in speed due to use of PI controller. If corrective action is not taken by the observer during this situation, the said undershoot results into saturation and it deteriorates dynamic behavior of BLDC motor.

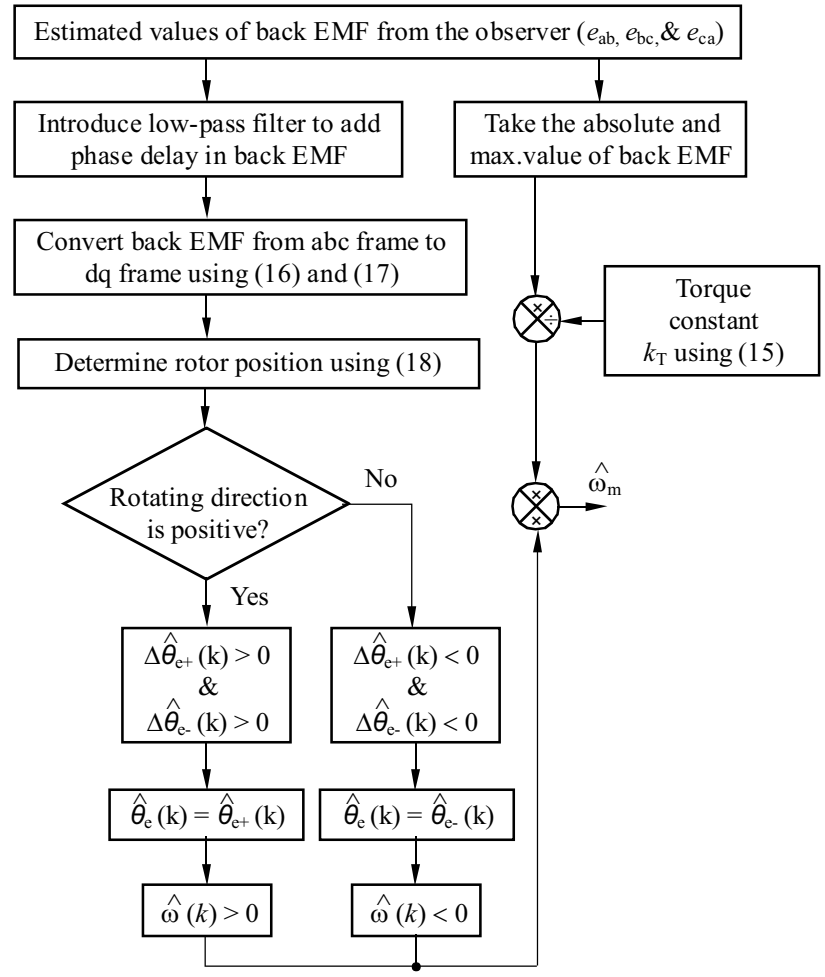

Fig. 4. Speed estimation algorithm for BLDC motor

This problem cannot be solved by using only (13). Therefore, to overcome this difficulty in practical applications, proposed speed estimation algorithm is suggested to control the dynamic behavior of BLDC motor. Figure 4 shows the speed estimation algorithm for BLDC motor which is implemented in this paper.

The low-pass filter is used to add phase delay in backEMF. Back EMF observer and low-pass filter are used for speed estimation algorithm. The line to line values of estimated back EMF is converted into dq form given by

$$
\widehat{e}_{d s}=\frac{1}{3}\left(\widehat{e}_{a b}-\widehat{e}_{c a}\right)
$$




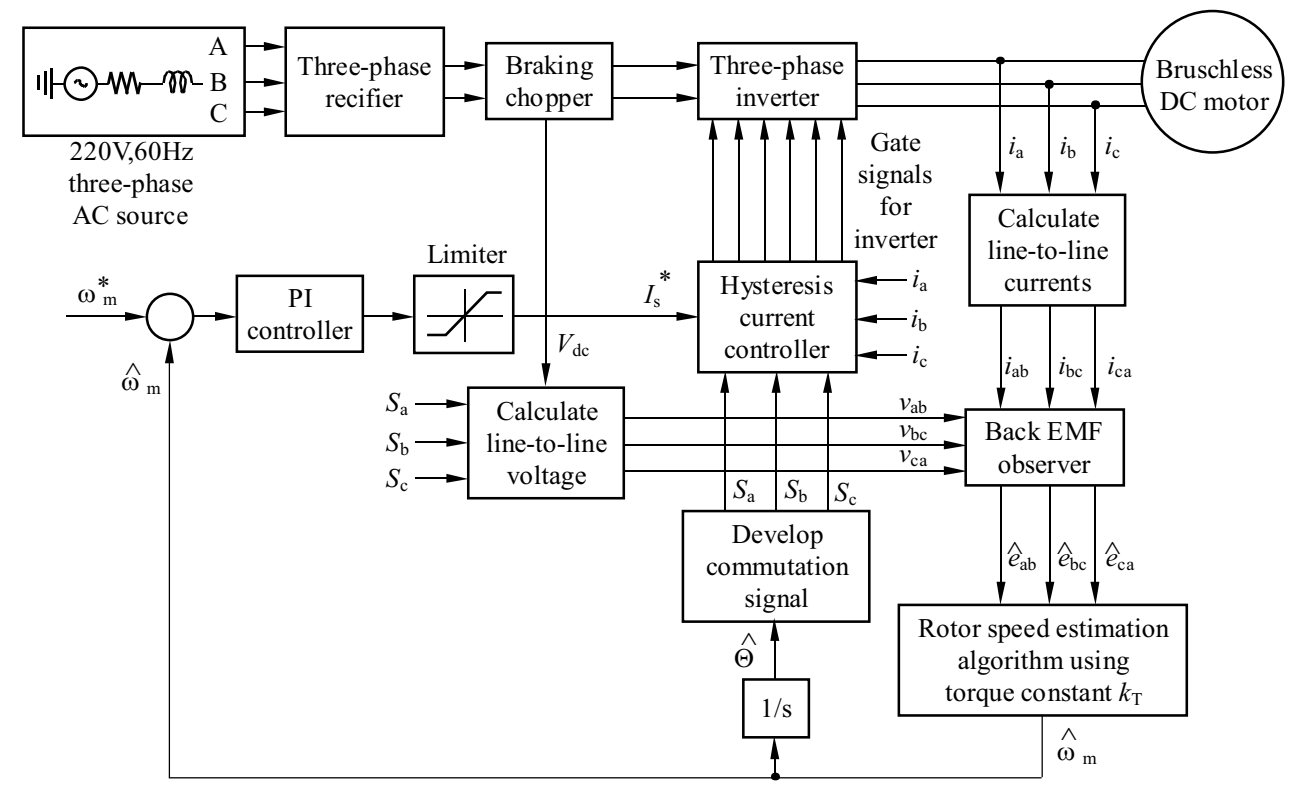

Fig. 5. Block diagram of the proposed sensorless control of BLDC motor

$$
\widehat{e}_{q s}=-\frac{1}{\sqrt{3}} \widehat{e}_{b c}
$$

The rotor position is determined from the dq components of back EMF and is given by

$$
\widehat{\theta}_{e}=\tan ^{-1}\left(\frac{\widehat{e}_{q s}}{\widehat{e}_{d s}}\right) .
$$

Now, suppose $\widehat{\theta}_{e+}(k)$ is the estimated rotor position for the positive direction of rotation and $\widehat{\theta}_{e-}(k)$ is the estimated rotor position for the negative direction of rotation. Angular displacements are obtained by comparing these values with their respective position values in the previous sampling instant as expressed by

$$
\begin{aligned}
\Delta \widehat{\theta}_{e+}(k) & =\widehat{\theta}_{e+}(k)-\widehat{\theta}_{e+}(k-1) \\
\Delta \widehat{\theta}_{e-}(k) & =\widehat{\theta}_{e-}(k)-\widehat{\theta}_{e-}(k-1)
\end{aligned}
$$

If the rotating direction is positive, the angular displacement $\Delta \widehat{\theta}_{e+}(k)>0$ and $\Delta \widehat{\theta}_{e-}(k)>0$. In this case, the actual rotor position $\widehat{\theta}_{e}(k)$ is equal to $\widehat{\theta}_{e+}(k)$ and speed direction is positive. If the rotating direction is negative, the angular displacement $\Delta \widehat{\theta}_{e+}(k)<0$ and $\Delta \widehat{\theta}_{e-}(k)<0$. In this case, the actual rotor position $\widehat{\theta}_{e}(k)$ is equal to $\widehat{\theta}_{e-}(k)$ and speed direction is negative.

\subsection{Block diagram representation of sensorless control of BLDC motor}

Figue 5 shows the overall block diagram of the proposed sensorless control for BLDC motor. The line to line voltage is found from DC-link voltage and commutation signals. The speed and rotor position are calculated using the estimated back EMF and proposed algorithm (Fig. 4). Estimated speed is fed to the error detector from which the difference between actual and desired value of speed can be find out. This output is fed to the PI controller which decides the current set value depending upon the gain values of controller. The torque reference divided by the torque constant $k_{T}$ would give a reference stator current $I_{s} *$. The gate signals for IGBTs are generated using commutation signals and comparing the actual and reference current through the hysteresis current controller. If the difference between reference and actual current go beyond a set hysteresis band, the upper switch of threephase inverter is turned on and the lower switch is turned off. As these difference crosses the lower band limit, the upper switch is turned off and the lower switch is turned on. The logic for the generation of gate pulses for the inverter is shown in Appendix. These gate signals decide exact voltage to be applied across the BLDC motor.

\section{Simulation results and discussions}

Various simulations have been carried out on brushless dc motor to validate the effect of observer and speed estimation algorithm on its dynamic performance. The effects of different values of observer gain along with the variations in rotor reference speed and load torque have been evaluated in the proposed work. The parameters of BLDC motor used in MATLAB/Simulink environment are given in Table 2 (Appendix).

In this work, the gains of the observer are calculated by limiting the real part of the eigenvalue to the certain extent in order to reduce the effect of disturbance and noise. Ackermans method was used to calculate the observer gains. The following cases are considered for the validation of the proposed methods. 

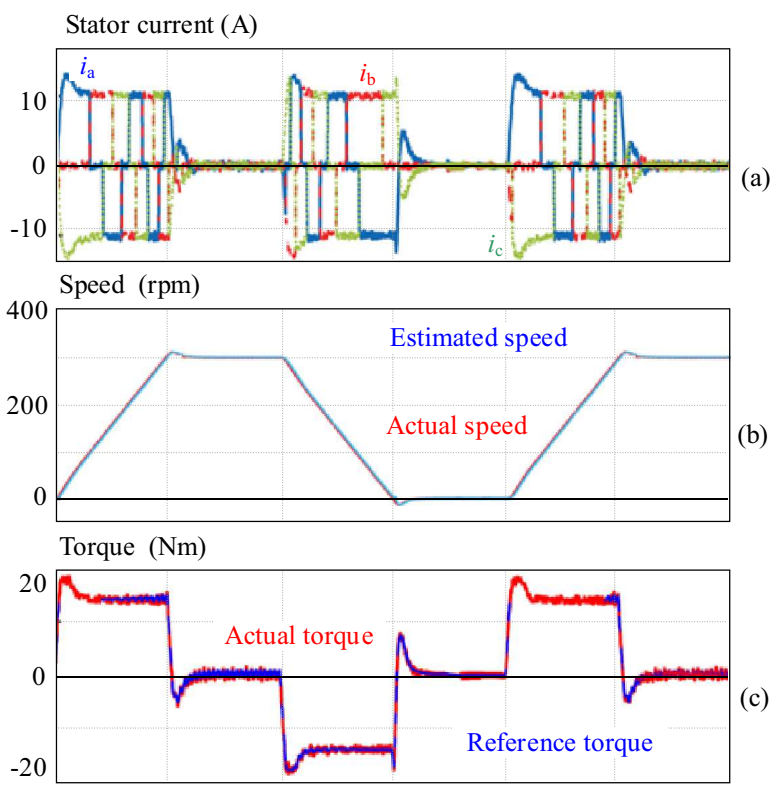

Line to line back EMF (V)

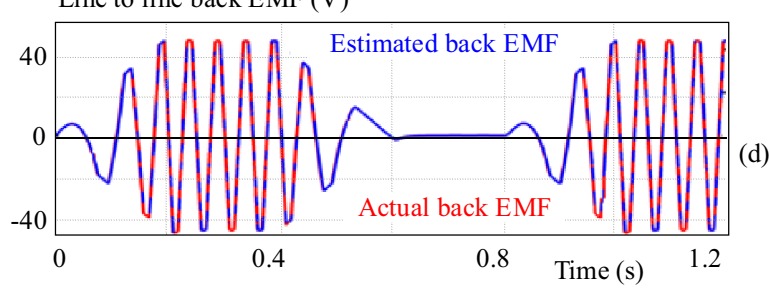

Fig. 6. Dynamic responses of stator currents, speeds, torques and back EMFs of phase-ab for the changes in reference speed from 300 rpm to $0 \mathrm{rpm}$ and again to $300 \mathrm{rpm}$, keeping load torque $\left(T_{L}\right)=0$

6.1 Step changes in reference speed from $300 \mathrm{rpm}$ to 0 rpm and again $300 \mathrm{rpm}$ for every $0.4 \mathrm{~s}$, with load torque equal to zero

Figure 6 shows the variations in stator currents, rotor speeds, torques and back EMFs of phase-ab for the case under consideration. The gains of the observer are set at $g_{1}=1976.47$ and $g_{2}=-20740$. From Fig. 6(a), it is observed that only two windings are conducting at any time and third winding current is zero, which exactly matches with the response shown in Fig. 2 and polarity of currents given in Table 1.

The variations in actual and estimated rotor speed can also be observed in Fig. 6(b), which indicate that for every step change in rotor reference speed, the estimated and actual speed always keep tracking with the rotor reference speed. This proves the effectiveness of the speed estimation algorithm with the proper gain settings of the observer. The actual torque successfully tracks the reference torque at all instants even during step changes in the rotor reference speed which can be observed from Fig. 6 (c). Similarly as shown in Fig. 6(d), the actual back EMF tries to track the estimated back EMF at all instants even during step changes in rotor reference speed.
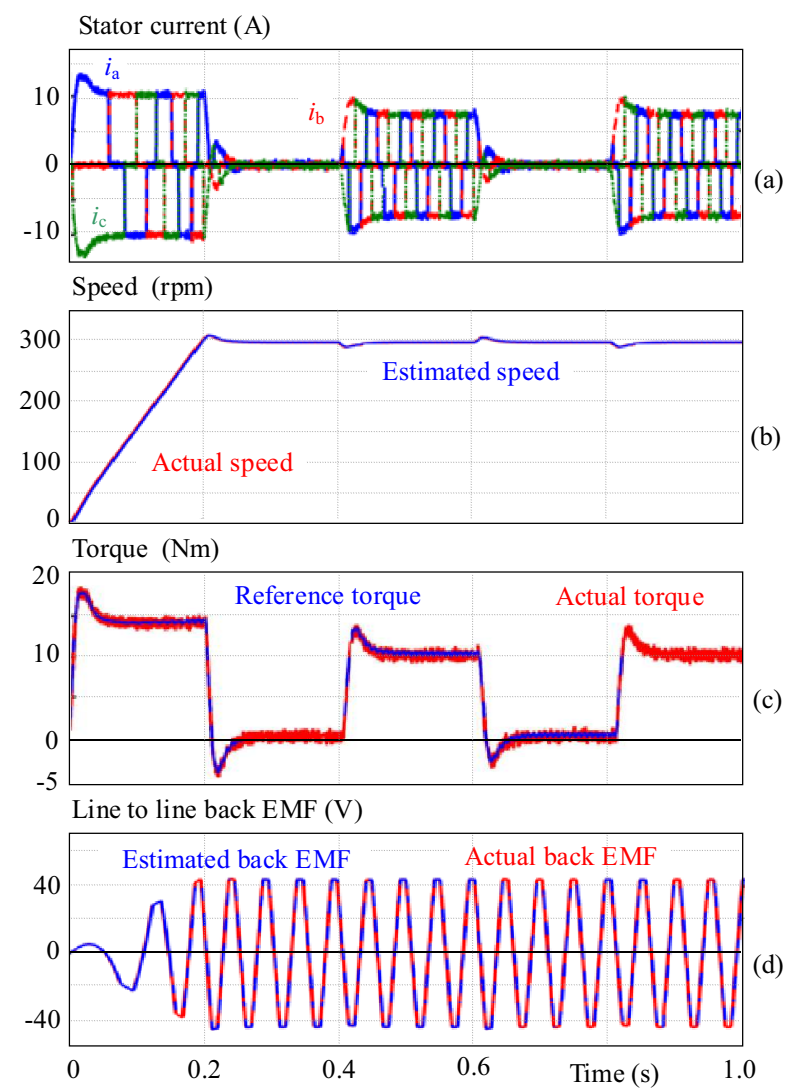

Fig. 7. Dynamic responses of stator currents, speeds, torques and back EMFs of phase-ab for the changes in load torque $\left(T_{L}\right)$ from $10 \mathrm{Nm}$ to $0 \mathrm{Nm}$ to $10 \mathrm{Nm}$ keeping reference speed at $300 \mathrm{rpm}$

6.2 Step changes in load torque from $10 \mathrm{~nm}$ to $0 \mathrm{~nm}$ to $10 \mathrm{~nm}$, with rotor reference speed set at $300 \mathrm{rpm}$

As shown in Fig. 7(b), the BLDC motor starts at $0 \mathrm{~s}$ and gradually attains $300 \mathrm{rpm}$ within $0.2 \mathrm{~s}$ and remains $300 \mathrm{rpm}$ up to $0.4 \mathrm{~s}$. In Fig. 7(c), with the change in load torque from rated steady state torque to $10 \mathrm{Nm}$ at $0.4 \mathrm{~s}$, an increase in stator currents is observed as shown in Fig. 7(a). At $0.6 \mathrm{~s}$, the load torque is set to $0 \mathrm{Nm}$ with the associated changes in stator currents. Similar responses are found for further change in load torque at $0.8 \mathrm{~s}$. The momentarily change in rotor speed can be seen from Fig. 7(b) with the change in load torque and after that the rotor attains its reference speed. The variations in actual back EMF of phase-ab also keep tracking with estimated back EMF as shown in Fig. 7(d). Here, the values of observer gains $g_{1}$ and $g_{2}$ remain as mentioned in section 6.1 .

\subsection{Effects of variation in observer gains on the dy- namic performance of the motor}

The relative difference between actual and estimated values of rotor speed, back EMF and rotor position are depicted in Figs 8-13 with variation in observer gains. Following two cases are considered. 

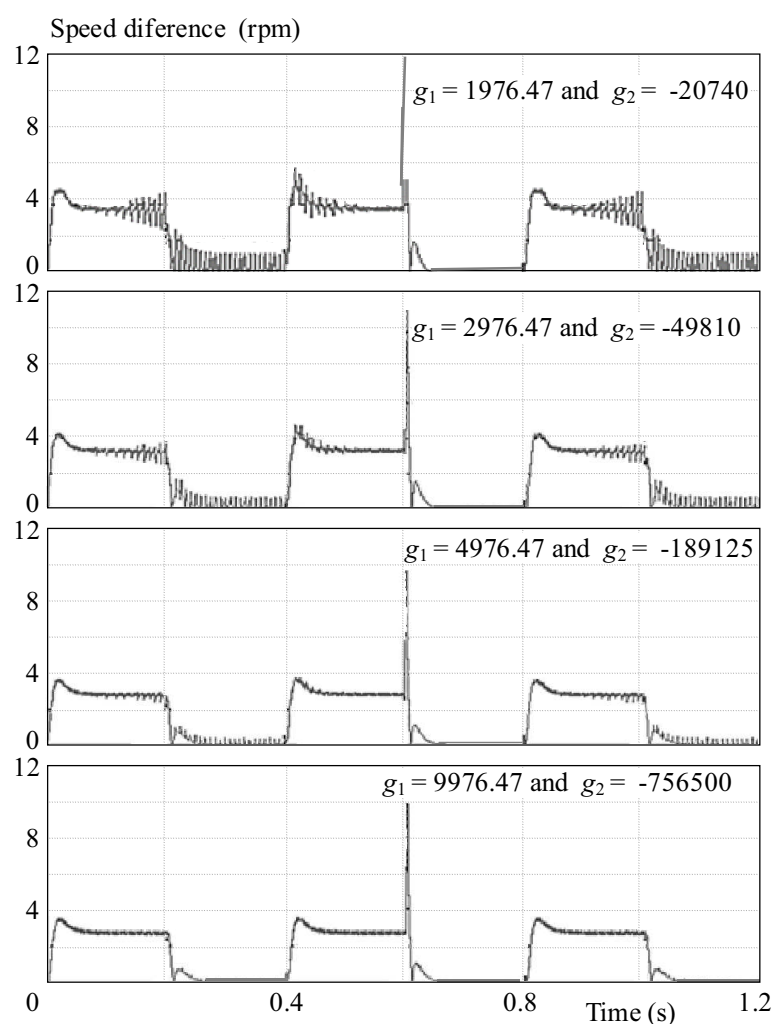

Fig. 8. Dynamic responses of difference between actual and estimated speed due to changes in reference speed from $300 \mathrm{rpm}$ to 0 rpm to $300 \mathrm{rpm}$, keeping load torque $\left(T_{L}\right)=0 \mathrm{Nm}$ with different observer gains

Rotor position difference (rad)
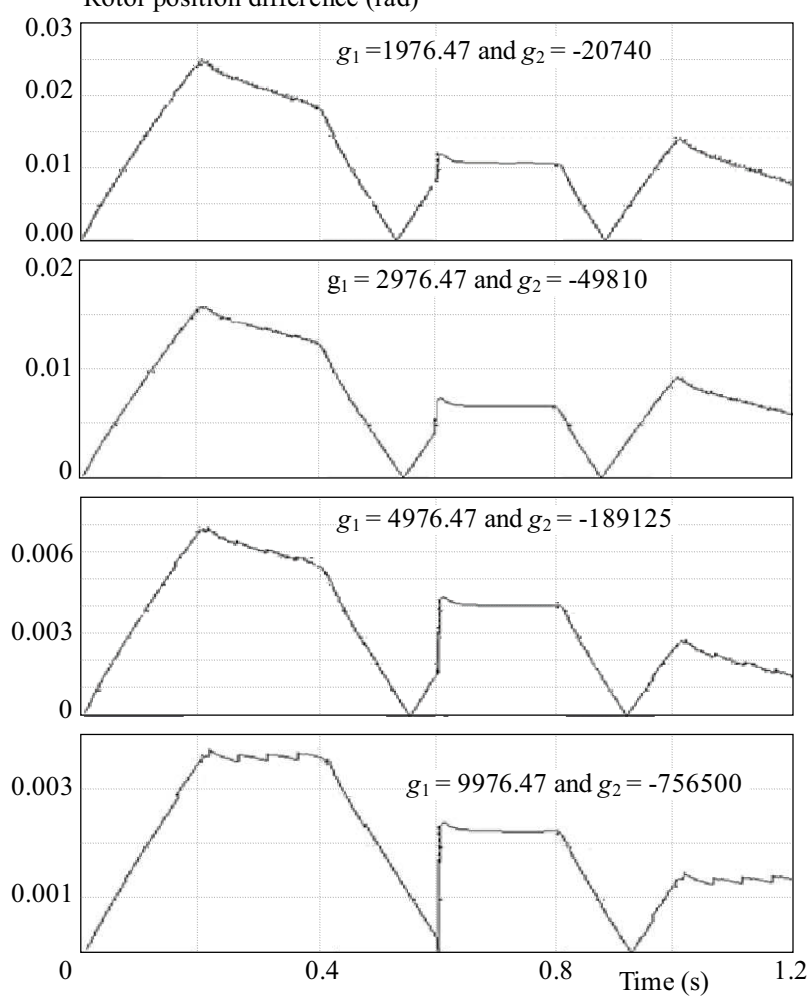

Fig. 10. Dynamic responses of difference between actual and estimated rotor position due to changes in reference speed from 300 $\mathrm{rpm}$ to $0 \mathrm{rpm}$ to $300 \mathrm{rpm}$, keeping load torque $\left(T_{L}\right)=0 \mathrm{Nm}$ with different observer gains
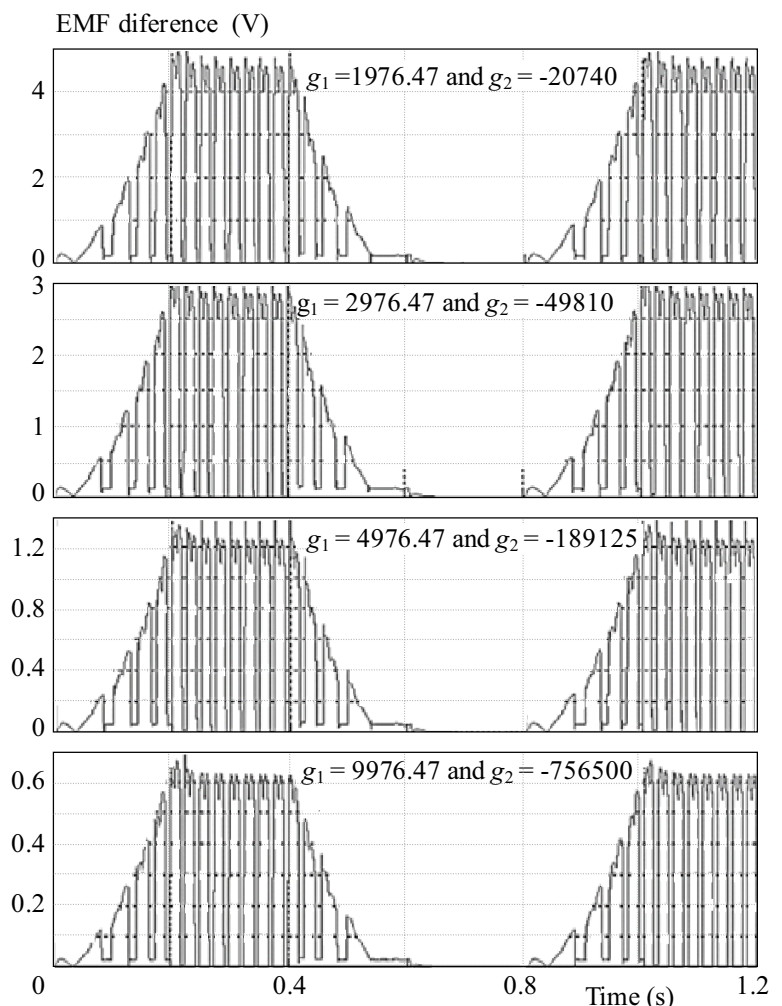

Fig. 9. Dynamic responses of difference between actual and estimated back EMF of phase-ab due to changes in reference speed from $300 \mathrm{rpm}$ to $0 \mathrm{rpm}$ to $300 \mathrm{rpm}$, keeping load torque $\left(T_{L}\right)=0$ $\mathrm{Nm}$ with different observer gains
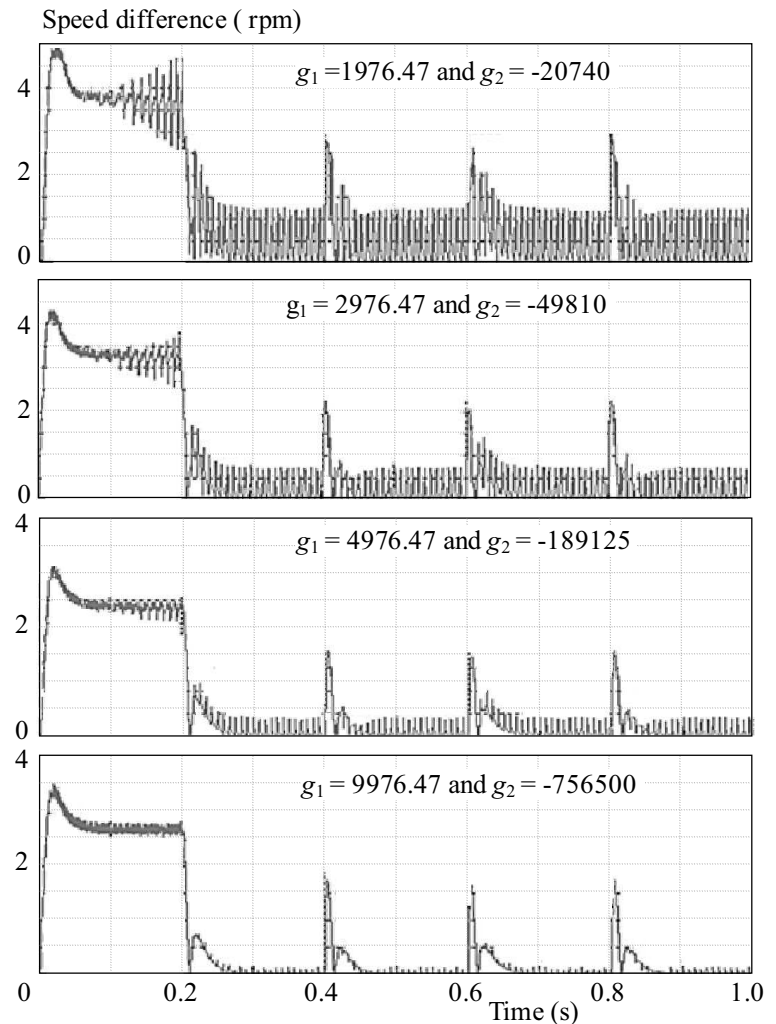

Fig. 11. Dynamic responses of difference between actual and estimated speed due to changes in load torque $\left(T_{L}\right)$ from $10 \mathrm{Nm}$ to $0 \mathrm{Nm}$ to $10 \mathrm{Nm}$, keeping reference speed at $300 \mathrm{rpm}$ with different observer gains 


\subsubsection{Rotor reference speed is changed from $300 \mathrm{rpm}$} to $0 \mathrm{rpm}$ to $300 \mathrm{rpm}$ for every $0.4 \mathrm{~s}$, with varying observer gains

As we move from first window to last window of Fig. 8, the transient response reveals that the difference between actual and estimated rotor speed gradually reduces with the selection of higher values of gains. Also, it is revealed from Fig. 8 that the oscillations are completely damped out and the difference between actual and estimated rotor speed becomes zero in steady state with higher values of gains as compared to the lower one.

When the rotor reference speed is changed from 300 rpm to $0 \mathrm{rpm}$, the actual and estimated speeds become negative due to action of PI controller at $t=0.6 \mathrm{~s}$. This causes the sudden change in the difference between actual and estimated rotor speed. The higher values of gains can reduce this sudden change as shown in Fig. 8.

The response of the difference between actual and estimated back EMF of phase-ab is shown in Fig. 9 with variation in observer gains. Initially the motor attains its rated speed of $300 \mathrm{rpm}$ within $0.2 \mathrm{~s}$ and remains constant up to $0.4 \mathrm{~s}$. During this period when the motor speed approaches its rated speed, the difference between actual and estimated back EMF increases gradually and remains maximum. The step changes in rotor reference speed from $300 \mathrm{rpm}$ to $0 \mathrm{rpm}$ is applied at $0.4 \mathrm{~s}$. It can be seen from the Fig. 9 that the difference of the said
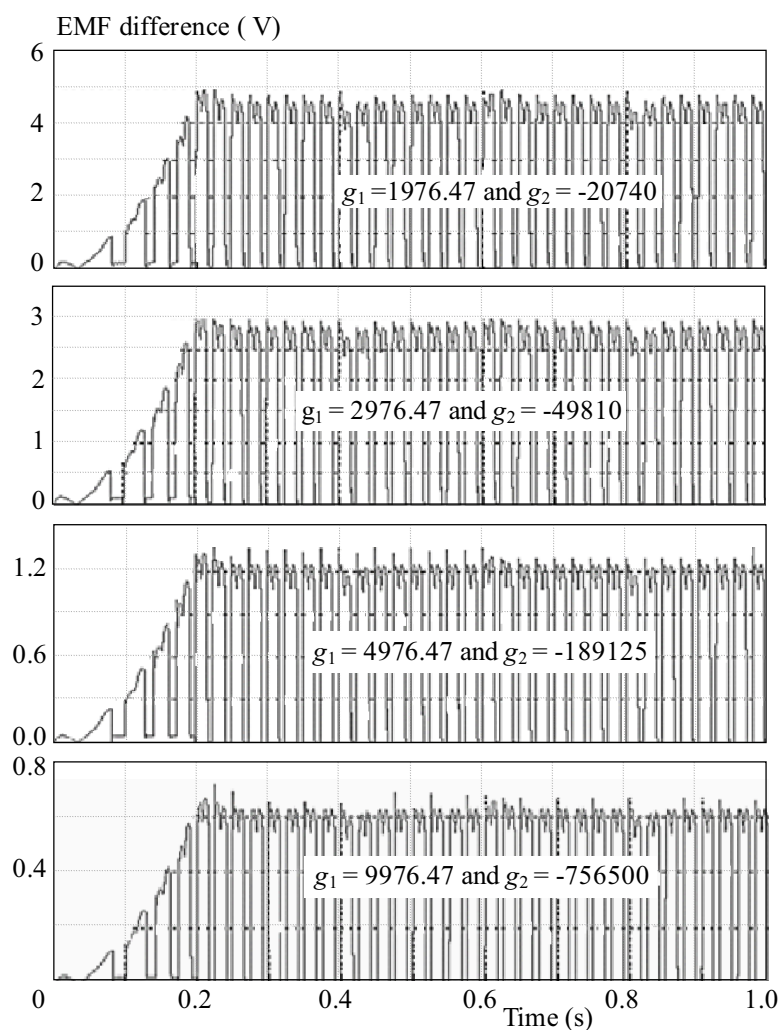

Fig. 12. Dynamic responses of difference between actual and estimated back EMF of phase - ab due to changes in load torque $\left(T_{L}\right)$ from $10 \mathrm{Nm}$ to $0 \mathrm{Nm}$ to $10 \mathrm{Nm}$, keeping reference speed at $300 \mathrm{rpm}$ with different observer gains two back EMF starts decreasing during this change and becomes zero as long as the rotor reference speed is set to $0 \mathrm{rpm}$. The higher value of observer gains significantly reduces this difference of back EMF and improves the dynamic performance of the motor as depicted in Fig. 9. It has been observed from Fig. 10 that the responses of difference between actual and estimated rotor positions also vary with respect to change in observer gains. The choice of the higher values of observer gains again helps to minimize the difference between actual and estimated rotor positions.

\subsubsection{Step changes in load torque from $10 \mathrm{Nm}$ to $0 \mathrm{Nm}$ to $10 \mathrm{Nm}$ keeping rotor reference speed at 300 rpm with varying observer gains}

Step change is applied in load torque at different interval of time $i e$ rated steady state torque to $10 \mathrm{Nm}$ at $0.4 \mathrm{~s}, 10 \mathrm{Nm}$ to $0 \mathrm{Nm}$ at $0.6 \mathrm{~s}$ and $0 \mathrm{Nm}$ to $10 \mathrm{Nm}$ at $0.8 \mathrm{~s}$. The responses of the difference between actual and estimated rotor speed for the case under consideration is shown in Fig. 11. The choice of higher values of observer gains results in reduced difference and also minimizes the oscillations.

In this case, the changes in load torque causes a slight variation in rotor speed; hence the back EMF is also the least affected. As a result, the difference in actual and estimated back EMF of phase-ab remains maximum through-

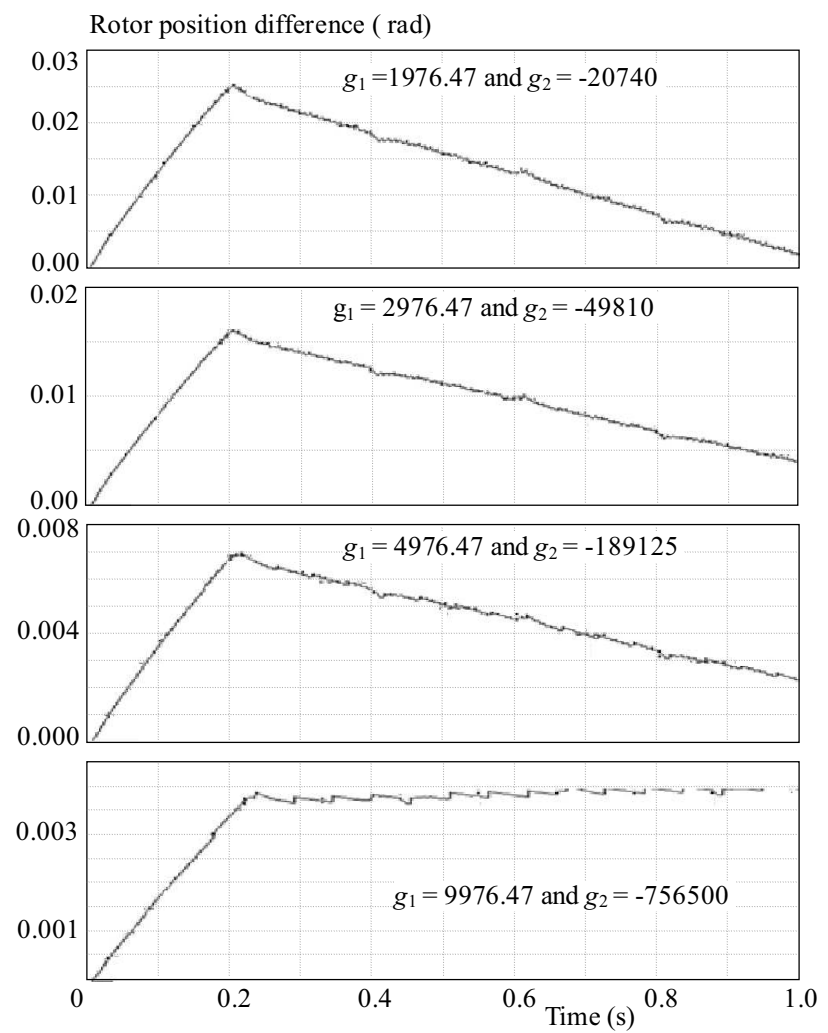

Fig. 13. Dynamic responses of difference between actual and estimated rotor position due to changes in load torque $\left(T_{L}\right)$ from 10 $\mathrm{Nm}$ to $0 \mathrm{Nm}$ to $10 \mathrm{Nm}$, keeping reference speed at $300 \mathrm{rpm}$ with different observer gains 
out the simulation as shown in Fig. 12. The higher values of observer gains significantly reduces the difference in back EMF and improves the dynamic behavior of the motor as depicted in Fig. 12 for the case under consideration. The satisfactorily responses are obtained for the rotor position difference with the higher values of observer gains as depicted in Fig. 13.

\section{Appendix}

Table 2. The logic for the generation of gate pulses for the inverter

\begin{tabular}{cll}
\hline Currents & \multicolumn{2}{c}{ Switches } \\
\hline$\left(i_{a}^{*}-i_{a}\right)>H B$ & $1 \mathrm{ON}$ & $2 \mathrm{OFF}$ \\
$\left(i_{a}^{*}-i_{a}\right)<H B$ & $1 \mathrm{OFF}$ & $2 \mathrm{ON}$ \\
$\left(i_{b}^{*}-i_{b}\right)>H B$ & $3 \mathrm{ON}$ & $4 \mathrm{OFF}$ \\
$\left(i_{b}^{*}-i_{b}\right)<H B$ & $3 \mathrm{OFF}$ & $4 \mathrm{ON}$ \\
$\left(i_{c}^{*}-i_{c}\right)>H B$ & $5 \mathrm{ON}$ & $6 \mathrm{OFF}$ \\
$\left(i_{c}^{*}-i_{c}\right)<H B$ & $5 \mathrm{OFF}$ & $6 \mathrm{ON}$ \\
\hline
\end{tabular}

where: $i_{a}^{*}, i_{b}^{*}$ and $i_{c}^{*}$ and $i_{a}, i_{b}$ and $i_{c}$ are the reference and the actual three phase stator currents respectively and HB is the hysteresis band.

Table 3. BLDC motor parameters

\begin{tabular}{lr}
\hline Stator resistance $\left(R_{s}\right)$ & $0.2 \Omega$ \\
Stator inductance $\left(L_{s}\right)$ & $8.5 \mathrm{mH}$ \\
Rotor inertia $(J)$ & $0.089 \mathrm{~kg} \mathrm{~m}^{2}$ \\
Friction $(B)$ & $0.005 \mathrm{Nm} \mathrm{s}$ \\
Number of pole pair $(p)$ & 4 \\
Rated speed $(\omega s)$ & $300 \mathrm{rpm}$ \\
Flux linkage established by magnets & $0.175 \mathrm{Vs}$ \\
Proportional Controller gain $\left(k_{p}\right)$ & 1.22 \\
Integral Controller gain $\left(k_{i}\right)$ & 46 \\
Current hysteresis bandwidth $(H B)$ & $0.01 \mathrm{~A}$ \\
\hline
\end{tabular}

\section{Conclusion}

This paper presents sensorless control method for the brushless dc motor with the use of the unknown input observer. The rotor position and speed can be estimated during transient as well as in steady state period from the line to line estimated back EMF without any additional hardware. The speed estimation algorithm has been successfully implemented in this paper and it gives guarantee to control the dynamic behavior of the motor during negative rotation. The criteria to choose eigenvalue is to obtain a balance between the faster convergence rate and the least noise level. Hence, observer gains cannot be increased to infinity. It has been observed that the higher values of the observer gain results in more accuracy. The effectiveness of the higher values of observer gains is verified for different disturbances such as changes in rotor reference speed and load torque. The dynamic responses of differences in rotor speed, back EMF and rotor position clearly depicts the lower overshoot and reduction in oscillations with higher value of observer gain. It is observed that the proposed algorithm can give accurate speed even near zero speed range. Moreover, the proposed algorithm accurately estimates the rotor position which exactly coincides with the actual rotor position.

\section{REFERENCES}

[1] P. Pillay and R. Krishnan, "Application characteristics of permanent magnet synchronous and brushless de motors for servo drives", IEEE Trans. Ind. Appl. , 27, no. 5, pp. 986-996, Sep/Oct 1991.

[2] N. Matsui, "Sensorless PM brushless dc motor drives", IEEE Trans. Ind. Electron. , 43, no. 2, pp. 300-308, 1996.

[3] K. Iizuka, H. Uzuhasashi, M. Kano, T. Endo and K. Mohri, "Microcomputer control for sensorless brushless motor", IEEE Trans. Ind. Appl. , IA-21, no. 3, pp. 595-601, May 1985.

[4] C. -T. Lin, C. -W. Hung and C. -W. Liu, "Sensorless control for four-switch three-phase brushless DC motor drive", Conf. Rec. IEEE IAS Annual Meeting, 4, pp. 2048-2053, 2006.

[5] J. X. Shen, Z. Q. Zhu and D. Howe, "Sensorless flux-weakening control of permanent-magnet brushless machines using third harmonic back EMF", IEEE Trans. Ind. Appl. , 40, no. 6, pp. 1629-1636, 2004.

[6] T. M. Jahns, R. C. Becerra and M. Ehsani, "Integrated current regulation for a brushless ECM drive", IEEE Trans. Power Electron. , 6, no. 1, pp. 118-126, January 1991.

[7] R. C. Becerra, T. M. Jahns and M. Ehsani, "Four-quadrant sensorless brushless ECM drive", Proc. APEC'91, pp. 202-209, 1991.

[8] J. X. Shen and S. Iwasaki, "Sensorless control of ultrahigh-speed PM brushless motor using PLL and third harmonic back EMF", IEEE Trans. Ind. Electron. , 53, no. 2, pp. 421-428, April 2006.

[9] N. Ertugrul and P. Acarnley, "A new algorithm for senseless operation of permanent magnet motors", IEEE Trans. Ind. Appl. , 30, no. 1, pp. 126-133, Jan/February 1994.

[10] R. Wu and G. R. Slemon, "A permanent magnet motor drive without a shaft sensor", IEEE Trans. Ind. Appl. , 27, no. 5, pp. 1005-1011, Sep/Oct 1991.

[11] S. Ogasawara and H. Akagi, "An approach to position sensorless drive for brushless de motors", IEEE Trans. Ind. Appl. , 27, no. 5, pp. 928-933, Sep/Oct 1991.

[12] B. Terzic and M. Jadric, "Design and implementation of the extended Kalman filter for the speed and rotor position estimation of brushless DC motor", IEEE Trans. Ind. Electron. , 48, no. 6, pp. 1065- 1073, December 2001.

[13] I. Janpan, R. Chaisricharoen and P. Boonyanant, "Control of the brushless dc motor combine mode", Procedia Engineering, pp. 279 - 285, 2012.

14] Chang-Liang and Xia, "Permanent magnet brushless DC motor drives and controls", John Wiley \& Sons Singapore Pte. Ltd. , 2012.

15] C. Debjyoti, C. Madhurima and R. Priyanka, "Modeling and simulation of cost effective sensorless drive for brushless dc motor", International conference on Computational Intelligence Modeling, Techniques and Applications (CIMTA- 2013), Procedia Technology 10, pp. 279 - 286, 2013. 
[16] R. S. Burns, "Advanced control engineering", Butterworth -Heinemann, 2001.

[17] A. K. Mandal, "Introduction to control engineering - modeling, analysis and design", New Age International Pvt. Ltd., 2006.

[18] G. S. Phadke, "Control system design", Vipul Prakashan, 2008.

[19] D. G. Luenberger, "An introduction to observer", IEEE Transaction on Automatic Control, Ac-16, no. 6, pp. 596-602, December 1971.

[20] J-W. Park, S. -H. Hwang and J. -M. Kim, "Sensorless control of brushless DC motors with torque constant estimation for home appliances", IEEE Trans. Ind. Appl. , 48, no. 2, pp. 677- 684, March/April 2012.

[21] R. Krishnan, "Permanent magnet synchronous and brushless DC motor drives", CRC Press, 2010.

Received 23 August 2016

Mitesh B. Astik, was born in 1980 in Gujarat, India. He received the $\mathrm{BE}$ degree in electrical engineering from Sardar Patel University, Gujarat, India in 2003, the ME degree in electrical engineering from Mumbai University, Maharashtra, India in 2006. He is currently working toward the $\mathrm{PhD}$ degree at C.S. Patel Institute of Technology, CHARUSAT, changa, Gujarat, India. Since 2008, he has been with the Department of Electrical Engineering, A.D. Patel Institute of Technology, India. His research interests are in the areas of electrical machines and electrical control systems. He is a member ofIndian Society of Technical Education (ISTE).

Praghnesh Bhatt was born in 1978 in Gujarat, India. He received BE degree in electrical engineering from L.D. College of Engineering, Gujarat University, Ahmedabad, India in1999,
ME degree in electrical power system from BVM Engineering College, Sardar Patel University, Vallabh Vidhyanagar, Gujarat, India in 2002 and received PhD from S.V. National Institute of Technology (SVNIT), Surat, Gujarat, India in 2012. He has published around 20 papers in journals and conferences at international and national levels. He is currently working as a Professor and Head of Department of electrical engineering, C.S. Patel Institute of Technology, CHARUSAT, Changa, Gujarat, India. His areas of interest are Power System Dynamics and Stability, Grid Integration of Wind Power Generation, Distributed Generation and Power System Protection. He is a member ofIEEE, IEEE Power and Energy Society and Indian Society of Technical Education (ISTE).

Bhavesh R. Bhalja was born in 1979 in Gujarat, India. He received $\mathrm{BE}$ degree in electrical engineering and $\mathrm{ME}$ degree in power system engineering from B.V.M. Engineering College, Sardar Patel University, Vallabh Vidyanagar, India in 1999 and 2001, respectively. He obtained PhD degree in electrical engineering from Indian Institute of Technology, Roorkee, India in 2007 and currently working as an Associate Professor in the department of electrical engineering, IIT Roorkee, India. He has published more than 50 papers in journals and conferences at international and national levels. His research interests include power system protection, automation, planning and design, system modeling and simulation and artificial intelligence. He is also involved in many research project funded by various research agencies. He got Young Engineers Award in 2009 by Institution of Engineers, India. 